\title{
Enzymatic Regional Methylation Assay: A Novel Method to Quantify Regional CpG Methylation Density
}

\author{
Oliver Galm, ${ }^{1,2}$ Michael R. Rountree, ${ }^{1,3}$ Kurtis E. Bachman, ${ }^{1}$ Kam-Wing Jair, ${ }^{1}$ \\ Stephen B. Baylin, ${ }^{1}$ and James G. Herman ${ }^{1,4}$ \\ ${ }^{1}$ Oncology Center, The Johns Hopkins Medical Institutions, Baltimore, Maryland 21231, USA; ${ }^{2}$ Medizinische Klinik IV, RWTH \\ Aachen, 52074 Aachen, Germany
}

\begin{abstract}
We have developed a novel quantitative method for rapidly assessing the $\mathrm{CpG}$ methylation density of a DNA region in mammalian cells. After bisulfite modification of genomic DNA, the region of interest is PCR amplified with primers containing two dam sites (GATC). The purified PCR products are then incubated with ${ }^{14} \mathrm{C}$-labeled S-adenosyl-L-methionine (SAM) and dam methyltransferase as an internal control to standardize DNA quantity. This is followed by an incubation with ${ }^{3} \mathrm{H}$-labeled SAM and Sssl methyltransferase for methylation quantification. By use of standard mixtures of cell line DNA with a defined methylation status in every assay, the ratio $\left({ }^{3} \mathrm{H} /{ }^{14} \mathrm{C}\right.$ signal) of each sample can be converted into percentage values to assess the methylation density of the amplified sequence. This methylation-sensitive technique, termed ERMA (Enzymatic Regional Methylation Assay) provides several advantages over existing methods used for methylation analysis as it determines an exact measurement of the methylation density of the region studied. We demonstrate a use of this technique in determining the methylation density of the promoter region of the tumor suppressor gene $p 15^{I N K A B}$ and changes that occur after treatment with demethylating agents.
\end{abstract}

In mammalian cells, DNA is methylated only at cytosines located $5^{\prime}$ to guanosine in the CpG dinucleotide (Holliday and Grigg 1993). DNA methylation plays an important role in genomic imprinting and $\mathrm{X}$-chromosome inactivation, and is essential for normal mammalian development (Constancia et al. 1998; Robertson and Jones 2000). Regional hypermethylation of CpG islands within promoter regions of tumor suppressor genes is associated with transcriptional inactivation and represents an important mechanism of gene silencing in the pathogenesis of neoplasia (Jones and Laird 1999; Baylin and Herman 2000). There is emerging evidence that the methylation profile of individual cancer types might have important prognostic implications for clinical monitoring, risk assessment, and even therapeutic considerations (Esteller et al. 2000; Nguyen et al. 2000; Wong et al. 2000; Chim et al. 2001). Furthermore, in clinical trials, the demethylating drug 5 'aza-2'-deoxycytidine (DAC) has been shown to be effective in patients with acute leukemia and myelodysplastic syndrome (Willemze et al. 1997; Wijermans et al. 2000).

Several methods have been developed to analyze the methylation status of DNA regions. In early studies, methylation patterns at individual CpG sites were determined by digestion of genomic DNA with methylation-sensitive restriction enzymes followed by Southern blotting (Feinberg and Vogelstein 1983). Most newer techniques utilize initial sodium bisulfite treatment of genomic DNA to distinguish

${ }^{3}$ Present address: Department of Molecular Pharmacology, St. Jude Children's Research Hospital, Memphis, TN 38105, USA.

${ }^{4}$ Corresponding author.

E-MAIL hermanji@jhmi.edu; FAX (410) 614-9884.

Article published on-line before print in December 2001: Genome Res., 10.1101/gr.202501.

Article and publication are at http://www.genome.org/cgi/doi/10.1101/ gr.202501. methylated from unmethylated cytosines prior to further analysis. This chemical modification, which converts all unmethylated cytosines to uracils, was the basis for genomic sequencing methods to analyze DNA methylation (Frommer et al. 1992; Clark et al. 1994). Bisulfite genomic sequencing includes all $\mathrm{CpG}$ dinucleotides within the amplified region, but has rarely been used quantitatively. Quantitative analysis of directly sequenced PCR products is difficult and imprecise, and large-scale sequencing of multiple plasmid clones is necessary to obtain overall methylation patterns and representative data for the tissue sample. Methylation-specific PCR (MSP) (Herman et al. 1996) has been used predominantly for qualitative gene promoter region methylation analysis of multiple tumor suppressor genes in various malignancies (Esteller et al. 2001). Bisulfite restriction analysis (Sadri and Hornsby 1996; Xiong and Laird 1997) and the Ms-SNuPE assay (Gonzalgo and Jones 1997) give quantitative information, but only individual CpG sites are analyzed. The combination of the MSP principle with real-time PCR technology (Lo et al. 1999; Eads et al. 2000; Muller-Tidow et al. 2001) is another quantitative strategy. However, these approaches quantitate only the proportion of alleles heavily methylated at primer and/or probe sequences.

We describe here a novel method for the quantification of CpG methylation density of a particular DNA region that has a number of advantages over existing technology. In contrast to many other protocols, this method determines the methylation density of the entire amplified region, not only of a few $\mathrm{CpG}$ sites or those $\mathrm{CpG}$ dinucleotides that are covered by PCR primers, and representative results for the tissue sample are obtained. This technique allows for the quantitative analysis of regional methylation density, which is representative of all allelic methylation patterns in the sample. 


\section{RESULTS}

\section{Principle of the Method}

Genomic DNA is initially treated with sodium bisulfite. In this reaction, all unmethylated cytosines are converted to uracils, but those that are methylated remain unchanged (Frommer et al. 1992). A DNA sequence of interest is then amplified with primers that are specific for bisulfite-modified DNA without CpG dinucleotides in their sequence, which ensures that the PCR amplification is independent of the original methylation status. All CpG dinucleotides remaining in the amplified region would thus represent methylated $\mathrm{CpG}$ sites in the original sequence. For quantification of $\mathrm{CpG}$ dinucleotides, we in vitro treated PCR products with the Escherichia coli cytosine methyltransferase SssI, which specifically methylates the cytosine in every $\mathrm{CpG}$ dinucleotide, using ${ }^{3} \mathrm{H}$-labeled $\mathrm{S}$ adenosyl-L-methionine (SAM) as a methyl group donor. The incorporation of ${ }^{3} \mathrm{H}$-methyl groups into the DNA is proportional to the number of methylated $\mathrm{CpG}$ sites originally present in this DNA region. To minimize the background signal and to remove residual radiolabeled SAM, we performed a clean-up step after the enzyme incubation and additional washing steps before scintillation counting. However, we found that these purification steps resulted in a variable loss of DNA in every reaction tube. Therefore, we devised a way to accurately standardize between samples. For this step, we introduced multiple GATC sites at the 5 ' end of our primers. The GATC sequence is the recognition site for the E. coli adenine methyltransferase dam. We then performed an additional step incubating the DNA with the dam enzyme, using ${ }^{14} \mathrm{C}$-labeled SAM as a methyl group donator. Because the number of GATC sites is identical for every PCR product (eight sites per double-stranded PCR product), the ${ }^{14} \mathrm{C}$ signal can be used as an internal control to standardize the amount of DNA that is finally analyzed. The results are expressed as the ratio of the scintillation counting signals of both radioisotopes $\left({ }^{3} \mathrm{H} /{ }^{14} \mathrm{C}\right)$. An overview of this approach is given in Figure 1. By use of cell lines with a known methylation density as standards, these ratios are converted into percentage values, and thus, the average methylation density of the amplified region can be determined.

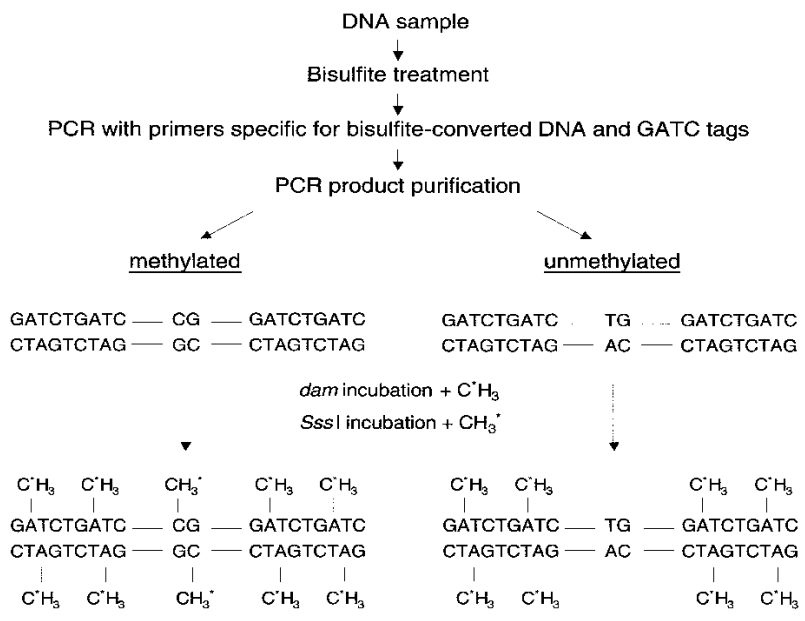

Figure 1 Outline for the analysis of gene promoter methylation density. For simplification, only one representative $\mathrm{CpG}$ dinucleotide within the amplified region is shown. $\mathrm{C}^{*} \mathrm{H}_{3}={ }^{14} \mathrm{C}$ methyl group; $\mathrm{CH}_{3}{ }^{*}={ }^{3} \mathrm{H}$ methyl group.

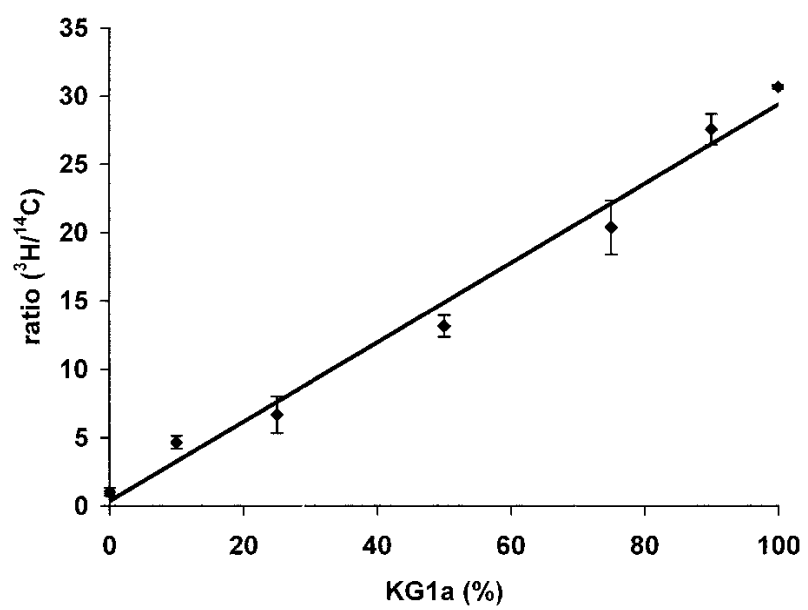

Figure 2 Mixing experiments using DNA form the cell lines KG1a and $\mathrm{HL60}$. The ratio $\left({ }^{3} \mathrm{H} /{ }^{14} \mathrm{C}\right.$ signal) is plotted against the percentage of KG1a DNA in the mixtures. The graph shows a linear relation between $p 15^{\text {INK } 4 B}$ promoter methylation density and the ratio $\left({ }^{3} \mathrm{H} /{ }^{14} \mathrm{C}\right.$ signal). Results are expressed as the mean value \pm SD of triplicates (correlation coefficient $=0.99$ ).

\section{Optimization of Assay Conditions for the $p 15^{I N K 4 B}$ Promoter Region}

After bisulfite treatment of genomic DNA, a 303-bp fragment of the $p 15^{I N K 4 B}$ promoter region was amplified by PCR using primers that were specific for bisulfite-converted DNA and tagged with two GATC sites at their $5^{\prime}$ ends. The resulting product was purified and sequentially incubated with the two bacterial methyltransferases dam and SssI in combination with the corresponding radiolabeled SAM. To establish the appropriate reaction conditions, we used serial dilutions of the leukemia cell lines KG1a, which has been shown to carry a fully methylated $p 15^{I N K 4 B}$ promoter region, and HL60, which has an unmethylated $p 15^{I N K 4 B}$ promoter region (Cameron et al. 1999b). Optimal amounts of radiolabeled SAM and methyltransferase concentrations were determined to allow reactions to go to completion.

To examine the sensitivity and quantitative accuracy of our assay as well as determining any possible PCR bias (Warnecke et al. 1997), we then performed mixing experiments using DNA from the cell lines KG1a and HL60. The DNA mixtures were prepared prior to bisulfite treatment in order to assess the possibility of bias during the PCR amplification. Figure 2 shows that there is a linear correlation between the defined methylation density of the standard cell line dilutions and the ${ }^{3} \mathrm{H} /{ }^{14} \mathrm{C}$ signal ratio. By including mixtures of cell lines as standards (KG1a only, 50\% KG1a/50\% HL60, and HL60 only, corresponding to $100 \%, 50 \%$, and $0 \%$ methylation density) in every assay, it is possible to create a standard curve in order to control for differential specific activity and incorporation efficiency of the radioisotopes. This standard curve can then be used to calculate the methylation density of unknown samples from the ratios $\left({ }^{3} \mathrm{H} /{ }^{14} \mathrm{C}\right.$ signal). All standards and unknown samples were analyzed in triplicate.

\section{Validation and Application}

To validate the accuracy of our approach, we analyzed the $p 15^{I N K 4 B}$ promoter methylation density in 13 samples from

\section{Genome Research




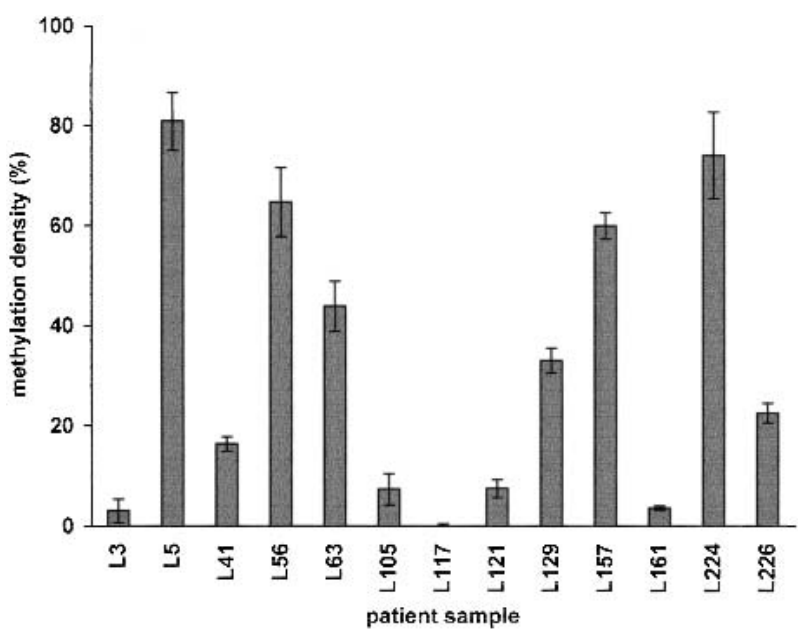

Figure $3 p 15^{I N K 4 B}$ promoter methylation densities of tumor samples from 13 patients with acute leukemia. Results are expressed as the mean value \pm SD of triplicates.

patients with acute leukemia. Figure 3 shows that this assay determined precisely the methylation density in every patient sample. When we compared these results with our previously reported bisulfite sequencing data of these same samples (Cameron et al. 1999b), we found a high concordance between the two methods (Fig. 4).

One potential application of our technique is the quantitation of methylation changes induced by treatment with demethylating agents. To demonstrate this use, we determined the in vitro effect of DAC on the $p 15^{I N K 4 B}$ promoter methylation density. KG1a cells, fully methylated in the $p 15^{I N K 4 B}$ promoter region, were harvested after a 72 -h incubation with various doses of DAC. We observed a dosedependent decrease in $p 15^{I N K 4 B}$ promoter methylation density (Fig. 5). After 0.1 and $0.5 \mu \mathrm{M}$ DAC treatment, the methylation density was reduced to $84.9 \%$ and $58.7 \%$, respectively. However, increasing the concentration to $1.0 \mu \mathrm{M}$ did not result in further demethylation of this region (57.2\%).

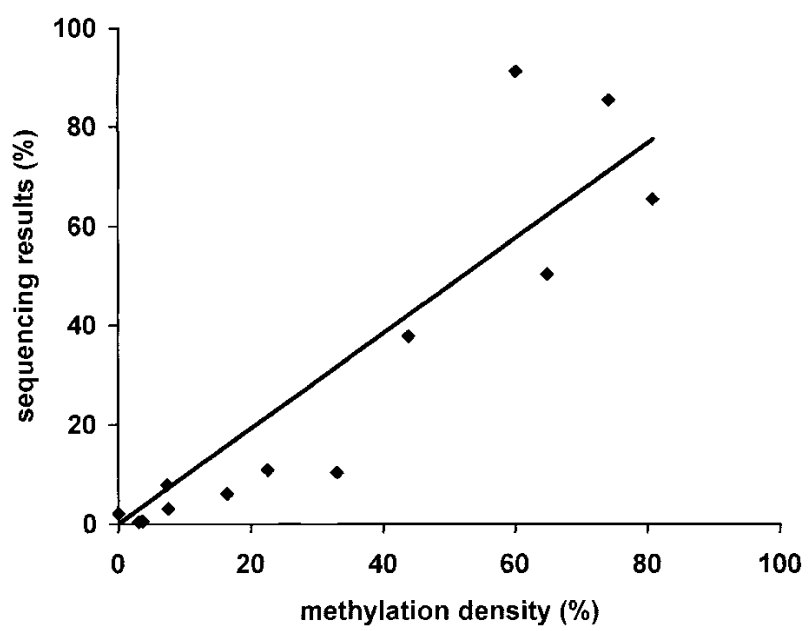

Figure 4 Correlation between bisulfite sequencing results (Cameron et al. 1999b) and methylation densities of the $p 15^{\text {INK4B }}$ promoter region as determined by our new assay in 13 patients with acute leukemia (correlation coefficient $=0.91$ ).

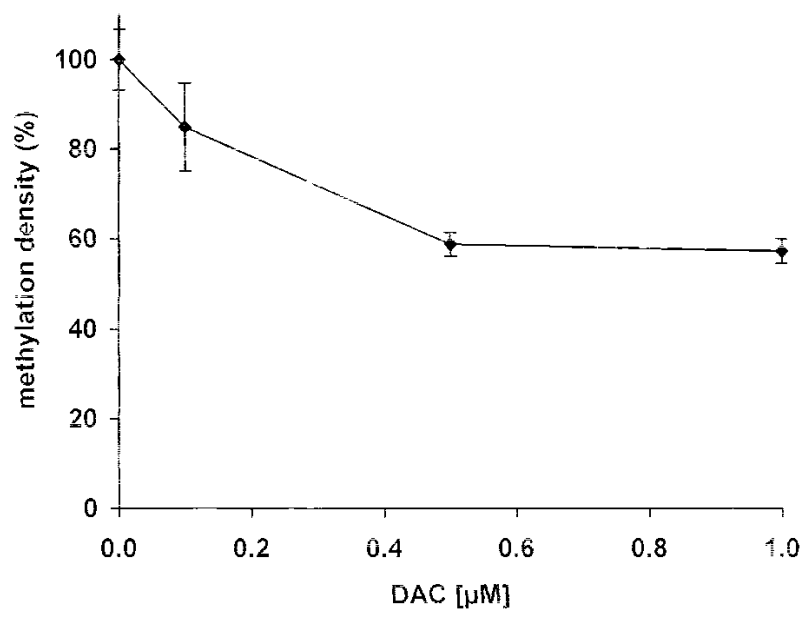

Figure 5 Influence of DAC treatment for $72 \mathrm{~h}$ on $p 15^{I N K 4 B}$ promoter methylation density in KG1a cells. Results are expressed as the mean value \pm SD of triplicates.

\section{DISCUSSION}

We describe a novel approach for quantitative analysis of CpG methylation density on the basis of the in vitro transfer of radiolabeled $\left({ }^{3} \mathrm{H}\right.$ and $\left.{ }^{14} \mathrm{C}\right)$ methyl groups to unmethylated target DNA sites using two bacterial methyltransferases. This method provides several advantages over existing strategies for quantitative methylation analysis: First, representative results for the tissue specimen are obtained, because not only a small number of alleles are analyzed. Furthermore, the methylation density of all CpG dinucleotides within the entire amplified region and not only of individual CpG sites is determined. In the case of the $p 15^{I N K 4 B}$ promoter region, the average methylation density of $30 \mathrm{CpG}$ dinucleotides was analyzed. Our assay produced a linear response when used for quantitative methylation analysis in mixing experiments by use of DNA from cell lines with a defined methylation status. Another feature of this technique is its precision. Several clean-up and washing steps contribute to minimize nonspecific radioactive signals. The use of an internal control allows for correction of potential substrate loss and for normalization of the results to the DNA amount that is finally analyzed by liquid scintillation counting. The accuracy of our new technique is shown by the high concordance with previously published bisulfite sequencing data of the $p 15^{I N K 4 B}$ promoter region from acute leukemia patients (Cameron et al. 1999b). However, in that study, only 14 alleles or less per patient sample were sequenced, and a different region of the $p 15^{I N K 4 B}$ promoter (between positions -215 and +421 relative to the transcription start site) was amplified, which might account for the slight discrepancies in methylation percentages. As cloning and final sequencing of a small number of alleles does not necessarily give representative data for the initial sample, the approach used in our current assay provides more information regarding the overall methylation density of the region from the sum of all alleles. Furthermore, the enzymatic regional methylation assay (ERMA) approach is less costly and labor intensive than the extensive bisulfite sequencing analysis needed for accurate quantitation. Therefore, this method is suitable for the high-throughput processing of multiple samples.

One limitation of our assay is that it does not determine 
the methylation status of individual CpG sites. However, as it has been found that the density of methylation is more important than methylation of single CpG sites for gene silencing (Hsieh 1994; Dodge et al. 1998; Bachman et al. 1999; Cameron et al. 1999b), results with our new assay might be more biologically relevant, especially in patient samples with heterogeneous methylation patterns. Furthermore, it was suggested in an in vitro model that de novo CpG island methylation is not a single event, but rather a progressive process, and appears to be region specific (Wong et al. 1999). Therefore, it is reasonable to apply a method that accurately determines the methylation density of a CpG island region in order to investigate the dynamics of methylation changes in human malignancies.

We have demonstrated the application of this new technique for the quantitative analysis of methylation density of the $p 15^{I N K 4 B}$ promoter region. When using this approach for different DNA regions, it is most convenient to use cell lines as standards, in which the detailed methylation status has been determined by other methods such as bisulfite sequencing. For the other candidate genes we have shown to be hypermethylated in cancer (Esteller et al. 2001), there are cell lines that are either fully methylated or unmethylated and thus can be used. An alternative approach to generate standards is to artificially methylate (using SssI and SAM) genomic DNA or the cloned sequence of interest prior to bisulfite treatment.

The evaluation of changes in methylation patterns following treatment with demethylating agents will be an important application of this new technique. It should prove valuable for exploring the in vivo mechanism of demethylating drugs, which have been shown to be effective in a variety of malignancies (Santini et al. 2001). Our in vitro data from KG1a cells indicate that increasing the 5'aza-2'deoxycytidine (DAC) dose beyond a certain level does not necessarily result in greater demethylating capacity within a given time course, but rather reaches a plateau phase of demethylation. These findings could help to optimize the dosage of demethylating drugs for clinical use by determining the extent of demethylation at a dose range with little cytotoxic side effects.

Recent studies indicate a synergism between CpG methylation and histone deacetylation for silencing of aberrantly methylated genes in cancer (Cameron et al. 1999a). Phase I studies using the combination of the demethylating agent 5-azacytidine and the histone deacetylase inhibitor phenylbutyrate in patients with high-risk myelodysplastic syndrome and acute myelogenous leukemia as well as solid tumors are ongoing at the Johns Hopkins Medical Institutions. Our novel technique will prove useful for the determination of methylation density in promoter regions of tumor suppressor genes in primary tumor samples that have been collected before and during treatment with these experimental drugs. This will help elucidate the consequences of treating patients with such drugs and eventually help clarify their therapeutic value in future antineoplastic therapy regimens.

Finally, our assay can be used to assess precisely the role of increasing methylation density of tumor suppressor genes in cancer progression, as has been suggested for $p 15^{I N K 4 B}$ in hematopoietic malignancies (Quesnel et al. 1998; Nguyen et al. 2000). The combination of our methylation density analysis with quantitative real-time PCR approaches to determine gene expression levels will contribute to more accurately as- sess the dynamics of methylation-mediated transcriptional silencing of tumor suppressor genes in carcinogenesis.

\section{METHODS}

\section{DNA Samples and Bisulfite Treatment}

DNA was extracted from leukemia cell pellets and cell lines as described previously (Cameron et al. 1999b). Sodium bisulfite treatment of DNA was performed according to the protocol of Herman et al. (1996).

\section{PCR Amplification and Purification}

By use of $100 \mathrm{ng}$ of resuspended, sodium bisulfite-treated DNA, PCR was performed in a $50-\mu \mathrm{L}$ reaction containing 400 $\mathrm{nM}$ of each primer (GIBCO BRL), $1 \times$ PCR buffer $(16.6 \mathrm{mM}$ ammonium sulfate/67 $\mathrm{mM}$ Tris at $\mathrm{pH} 8.8 / 6.7 \mathrm{mM} \mathrm{MgCl}_{2} / 10$ $\mathrm{mM}$ 2-mercaptoethanol) and $1.25 \mathrm{mM}$ of each dNTP (Pharmacia). Reactions were hot started at $95^{\circ} \mathrm{C}$ for $5 \mathrm{~min}$ and held at $80^{\circ} \mathrm{C}$ before addition of $1.25 \mathrm{U}$ of Taq polymerase (Sigma). Temperature conditions for PCR were as follows: 40 cycles of $95^{\circ} \mathrm{C}$ for $30 \mathrm{sec}, 58^{\circ} \mathrm{C}$ for $30 \mathrm{sec}$, and $72^{\circ} \mathrm{C}$ for $30 \mathrm{sec}$, followed by 1 cycle of $72^{\circ} \mathrm{C}$ for $5 \mathrm{~min}$. Primers used were $5^{\prime}$-AAGATC TGATCTGTTGAGTTTAGGTTTTTTAGGAAGGAGAG$3^{\prime}$ and 5'-AAGATCTGATCAAACCCTAAAACCCCAACT ACCTAAAT-3'. Primer sequences were specific for sodium bisulfite-converted DNA and both primers were tagged with two GATC sites at their 5 ' ends, resulting in the amplification of a 303-bp fragment of the $p 15^{I N K 4 B}$ promoter region (between positions +208 and +511 relative to the transcription start site). To avoid the introduction of artificial CpG dinucleotides into the PCR products, thymidines were inserted between the GATC sites.

PCR products were purified by use of a commercially available kit (QIAGEN) according to the manufacturer's recommendations. For quality control and quantitation, $1 \mu \mathrm{L}$ of the purified PCR products was loaded on a $2.5 \%$ agarose gel containing ethidium bromide and visualized under UV illumination.

\section{Methylation Density Assay}

In the first reaction, purified PCR products $(\sim 150 \mathrm{ng})$ were incubated with $93.75 \mathrm{nCi}^{14} \mathrm{C}-\mathrm{SAM}$ (Amersham) and $16 \mathrm{U}$ of dam methyltransferase (New England Biolabs) in $1 \times$ reaction buffer (50 mM Tris-HCl, $10 \mathrm{mM}$ EDTA, $5 \mathrm{mM}$ 2-mercaptoethanol; New England Biolabs) for $4 \mathrm{~h}$ at $37^{\circ} \mathrm{C}$. DNA was purified using G-50 spin mini-columns (BioMax) and precipitated in ethanol. Resuspended DNA was then incubated with $1.25 \mu \mathrm{Ci}$ ${ }^{3} \mathrm{H}-\mathrm{SAM}$ (Amersham), $80 \mu \mathrm{M}$ SAM (New England Biolabs), and $4 \mathrm{U}$ of SssI methyltransferase (New England Biolabs) in $1 \times$ reaction buffer $\left(50 \mathrm{mM} \mathrm{NaCl}, 10 \mathrm{mM}\right.$ Tris- $\mathrm{HCl}, 10 \mathrm{mM} \mathrm{MgCl}_{2}$, $1 \mathrm{mM}$ dithiothreitol; New England Biolabs) for $4 \mathrm{~h}$ at $37^{\circ} \mathrm{C}$. Following another spin mini-column clean-up step, DNA was spotted on GF/C filter discs (Whatman) and washed with 5\% trichloroacetic acid + BSA and 70\% ethanol prior to liquid scintillation counting (Beckman). Results are expressed as the mean disintegrations per minute (d.p.m.) in the ${ }^{3} \mathrm{H}$ channel divided by d.p.m. in the ${ }^{14} \mathrm{C}$ channel. All reactions were performed in triplicate.

\section{ACKNOWLEDGMENTS}

This work was supported by NIH grants CA87760 and CA84986. O.G. was supported by an intramural grant from the RWTH Aachen.

The publication costs of this article were defrayed in part by payment of page charges. This article must therefore be hereby marked "advertisement" in accordance with 18 USC section 1734 solely to indicate this fact. 


\section{REFERENCES}

Bachman, K.E., Herman, J.G., Corn, P.G., Merlo, A., Costello, J.F., Cavenee, W.K., Baylin, S.B., and Graff, J.R. 1999. Methylation-associated silencing of the tissue inhibitor of metalloproteinase-3 gene suggest a suppressor role in kidney, brain, and other human cancers. Cancer Res. 59: 798-802.

Baylin, S.B. and Herman, J.G. 2000. DNA hypermethylation in tumorigenesis: Epigenetics joins genetics. Trends Genet. 16: $168-174$

Cameron, E.E., Bachman, K.E., Myohanen, S., Herman, J.G., and Baylin, S.B. 1999a. Synergy of demethylation and histone deacetylase inhibition in the re-expression of genes silenced in cancer. Nat. Genet. 21: 103-107.

Cameron, E.E., Baylin, S.B., and Herman, J.G. 1999b. p15(INK4B) CpG island methylation in primary acute leukemia is heterogeneous and suggests density as a critical factor for transcriptional silencing. Blood 94: 2445-2451.

Chim, C.S., Liang, R., Tam, C.Y., and Kwong, Y.L. 2001. Methylation of p15 and p16 genes in acute promyelocytic leukemia: Potential diagnostic and prognostic significance. J. Clin. Oncol. 19: $2033-2040$

Clark, S.J., Harrison, J., Paul, C.L., and Frommer, M. 1994. High sensitivity mapping of methylated cytosines. Nucleic Acids Res. 22: 2990-2997.

Constancia, M., Pickard, B., Kelsey, G., and Reik, W. 1998. Imprinting mechanisms. Genome Res. 8: 881-900.

Dodge, J.E., List, A.F., and Futscher, B.W. 1998. Selective variegated methylation of the p15 CpG island in acute myeloid leukemia. Int. J. Cancer 78: 561-567.

Eads, C.A., Danenberg, K.D., Kawakami, K., Saltz, L.B., Blake, C., Shibata, D., Danenberg, P.V., and Laird, P.W. 2000. MethyLight: A high-throughput assay to measure DNA methylation. Nucleic Acids Res. 28: E32.

Esteller, M., Garcia-Foncillas, J., Andion, E., Goodman, S.N., Hidalgo, O.F., Vanaclocha, V., Baylin, S.B., and Herman, J.G. 2000. Inactivation of the DNA-repair gene MGMT and the clinical response of gliomas to alkylating agents. N. Engl. J. Med. 343: $1350-1354$.

Esteller, M., Corn, P.G., Baylin, S.B., and Herman, J.G. 2001. A gene hypermethylation profile of human cancer. Cancer Res. 61: $3225-3229$.

Feinberg, A.P. and Vogelstein, B. 1983. Hypomethylation distinguishes genes of some human cancers from their normal counterparts. Nature 301: 89-92.

Frommer, M., McDonald, L.E., Millar, D.S., Collis, C.M., Watt, F., Grigg, G.W., Molloy, P.L., and Paul, C.L. 1992. A genomic sequencing protocol that yields a positive display of 5-methylcytosine residues in individual DNA strands. Proc. Natl. Acad Sci. 89: 1827-1831.

Gonzalgo, M.L. and Jones, P.A. 1997. Rapid quantitation of methylation differences at specific sites using methylation-sensitive single nucleotide primer extension (Ms-SNuPE). Nucleic Acids Res. 25: 2529-2531.

Herman, J.G., Graff, J.R., Myohanen, S., Nelkin, B.D., and Baylin, S.B. 1996. Methylation-specific PCR: A novel PCR assay for methylation status of CpG islands. Proc. Natl. Acad. Sci. 93: 9821-9826.

Holliday, R. and Grigg, G.W. 1993. DNA methylation and mutation. Mutat. Res. 285: 61-67.
Hsieh, C.L. 1994. Dependence of transcriptional repression on CpG methylation density. Mol. Cell. Biol. 14: 5487-5494.

Jones, P.A. and Laird, P.W. 1999. Cancer epigenetics comes of age. Nat. Genet. 21: 163-167.

Lo, Y.M., Wong, I.H., Zhang, J., Tein, M.S., Ng, M.H., and Hjelm, N.M. 1999. Quantitative analysis of aberrant p16 methylation using real-time quantitative methylation-specific polymerase chain reaction. Cancer Res. 59: 3899-3903.

Muller-Tidow, C., Bornemann, C., Diederichs, S., Westermann, A., Klumpen, S., Zuo, P., Wang, W., Berdel, W.E., and Serve, H. 2001. Analyses of the genomic methylation status of the human cyclin A1 promoter by a novel real-time PCR-based methodology. FEBS Lett. 490: 75-78.

Nguyen, T.T., Mohrbacher, A.F., Tsai, Y.C., Groffen, J., Heisterkamp, N., Nichols, P.W., Yu, M.C., Lubbert, M., and Jones, P.A. 2000. Quantitative measure of c-abl and p15 methylation in chronic myelogenous leukemia: Biological implications. Blood 95: 2990-2992.

Quesnel, B., Guillerm, G., Vereecque, R., Wattel, E., Preudhomme, C., Bauters, F., Vanrumbeke, M., and Fenaux, P. 1998. Methylation of the p15(INK4b) gene in myelodysplastic syndromes is frequent and acquired during disease progression. Blood 91: 2985-2990.

Robertson, K.D. and Jones, P.A. 2000. DNA methylation: Past, present and future directions. Carcinogenesis 21: 461-467.

Sadri, R. and Hornsby, P.J. 1996. Rapid analysis of DNA methylation using new restriction enzyme sites created by bisulfite modification. Nucleic Acids Res. 24: 5058-5059.

Santini, V., Kantarjian, H.M., and Issa, J.P. 2001. Changes in DNA methylation in neoplasia: Pathophysiology and therapeutic implications. Ann. Intern. Med. 134: 573-586.

Warnecke, P.M., Stirzaker, C., Melki, J.R., Millar, D.S., Paul, C.L., and Clark, S.J. 1997. Detection and measurement of PCR bias in quantitative methylation analysis of bisulphite-treated DNA. Nucleic Acids Res. 25: 4422-4426.

Wijermans, P., Lubbert, M., Verhoef, G., Bosly, A., Ravoet, C., Andre, M., and Ferrant, A. 2000. Low-dose 5-aza-2'-deoxycytidine, a DNA hypomethylating agent, for the treatment of high-risk myelodysplastic syndrome: A multicenter phase II study in elderly patients. J. Clin. Oncol. 18: 956-962.

Willemze, R., Suciu, S., Archimbaud, E., Muus, P., Stryckmans, P., Louwagie, E.A., Berneman, Z., Tjean, M., Wijermans, P., Dohner, H., et al. 1997. A randomized phase II study on the effects of 5-Aza-2'-deoxycytidine combined with either amsacrine or idarubicin in patients with relapsed acute leukemia: An EORTC Leukemia Cooperative Group phase II study (06893). Leukemia 11: S24-S27.

Wong, D.J., Foster, S.A., Galloway, D.A., and Reid, B.J. 1999. Progressive region-specific de novo methylation of the p16 CpG island in primary human mammary epithelial cell strains during escape from M(0) growth arrest. Mol. Cell. Biol. 19: 5642-5651.

Wong, I.H., Ng, M.H., Huang, D.P., and Lee, J.C. 2000. Aberrant p15 promoter methylation in adult and childhood acute leukemias of nearly all morphologic subtypes: Potential prognostic implications. Blood 95: 1942-1949.

Xiong, Z. and Laird, P.W. 1997. COBRA: A sensitive and quantitative DNA methylation assay. Nucleic Acids Res. 25: 2532-2534.

Received June 27, 2001; accepted in revised form August 23, 2001.
Genome Research www.genome.org 


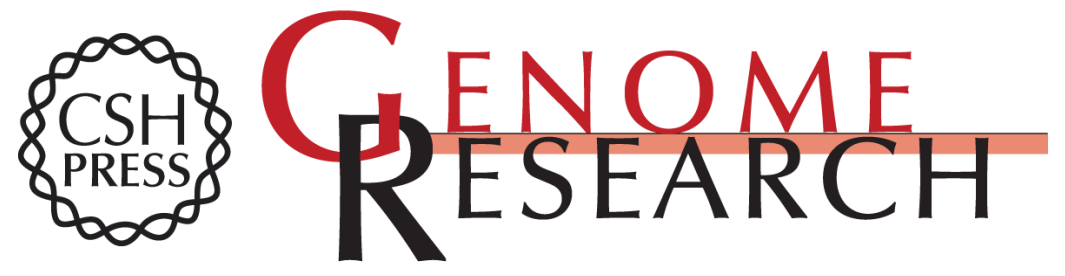

\section{Enzymatic Regional Methylation Assay: A Novel Method to Quantify Regional CpG Methylation Density}

Oliver Galm, Michael R. Rountree, Kurtis E. Bachman, et al.

Genome Res. 2002 12: 153-157

Access the most recent version at doi:10.1101/gr.202501

\section{License}

Email Alerting Service

Receive free email alerts when new articles cite this article - sign up in the box at the top right corner of the article or click here.

\section{Affordable, Accurate} Sequencing.

To subscribe to Genome Research go to: https://genome.cshlp.org/subscriptions 